\title{
К ВОПРОСУ ОБ ОЦЕНКЕ КОМПЕТЕНЦИЙ ЧЕЛОВЕЧЕСКОГО КАПИТАЛА
}

\section{ON THE ISSUE OF ASSESSING THE HUMAN CAPITAL COMPETENCIES}

\section{Melnichuk}

Summary. The modern transformation of society and its institutions, caused by the exponential growth of data and information technology, could not but touch upon the problems of the formation of human capital and the assessment of its competencies. As knowledge becomes the main resource of economic growth, education has become a condition for socioeconomic and intellectual prosperity. As a result, interest in understanding the value of intangible assets - human capital - continues to grow, and evaluating and managing the intellectual potential of employees is an important task both at the individual level and at the organization level. The educational potential of a person has a number of properties of investment (capital) goods and it is an important factor ensuring macroeconomic growth at the national and world level.

Keywords: human capital; intellectual capital; cyclical nature of science; paradigm shift.

\author{
Мельничук Марина Владимировна \\ Д.э.н., профессор, Финансовый университет при \\ Правительстве РФ \\ MVMelnichuk@fa.ru
}

Аннотация. Современное преобразование общества и его институтов, вызванное экспоненциальным ростом данных и информационных технологий, не могло не затронуть проблемы формирования человеческого капитала и оценки его компетенций. Поскольку основным ресурсом экономического роста становятся знания, образование стало условием социально-экономического и интеллектуального процветания. Как следствие, интерес к пониманию стоимости нематериальных активов - человеческого капитала - продолжает расти, а оценка и управление интеллектуальным потенциалом сотрудников является важной задачей как на уровне индивида, так и на уровне организации. Образовательный потенциал человека имеет ряд свойств инвестиционного (капитального) товара и является важным фактором, обеспечивающим макроэкономический рост на национальном и мировом уровне.

Ключевые слова: человеческий капитал; интеллектуальный капитал; цикличность науки; смена парадигм.

Под «парадигмой» или цикличностью Кун понимал следующее: появление и развитие знаний происходит в пространстве предпосылок, в первую очередь, в социальной среде, которая их генерирует. Среди предпосылок развития науки Кун выделяет методологические директивы или правила и стандарты, которыми руководствуются члены научного сообщества. При этом Кун отмечает, что, во-первых, директивы - это только один из инструментов развития науки, который не следует абсолютизировать. Во-вторых, директивы координируют научную деятельность, направляя ее в нужное русло. В-третьих, директивы имеют многоуровневую структуру, на верхнем ярусе которой - диалектические принципы, которые являются основой научного познания.

Согласно теории, сформулированной американским ученым Томасом Куном в книге «Структура научных революций» [3], наука развивается не линейно и поступательно, а в форме циклов или смены парадигм. Парадигма устанавливает понятийный инструментарий и главное направление научного исследования. Кун доказывает, что история науки - это не процесс накопления знаний, а альтернация периодов «нормальной науки» и «революционной науки».

Если попытаться представить графическое изображение модели Куна, то развитие науки будет выглядеть как цепь дискретных циклов, включающих четыре главных элемента: научная парадигма, научное сообщество, нормальная наука и научная революция.

Парадигма - центральное звено в модели - обеспечивает шаблоны и инструментарий для формулировки 
Таблица 1. Характеристики новой и современной парадигм [4-5]

\begin{tabular}{|c|c|c|}
\hline Аспект & Современная парадигма & Личностно ориентированная парадигма \\
\hline Общая концепция & Индустриальная эра & Сетевая эра \\
\hline Система отсчета & Заводы и конвейерная сборка & Информационные сети и горизонтальные связи \\
\hline Модель & $\begin{array}{l}\text { В центре - учебное заведение: } \\
\text { компоненты всей системы нацелены } \\
\text { на предоставление образовательных услуг } \\
\text { в рамках стандартных школ и вузов }\end{array}$ & $\begin{array}{l}\text { Личностно ориентированный подход: } \\
\text { все элементы обеспечивают получение } \\
\text { образования, адаптированного к потребностям } \\
\text { и потенциалу каждого отдельного студента } \\
\text { с целью максимального повышения качества } \\
\text { образования каждого студента } \\
\end{array}$ \\
\hline Компоненты модели & $\begin{array}{l}\text { Стандартные возрастные группы } \\
\text { Линейные учебные планы по каждому } \\
\text { предмету } \\
\text { Школы, функционирующие как «фабрики } \\
\text { образования» } \\
\text { Качество обучения обеспечивает } \\
\text { получение знаний в рамках традиционных } \\
\text { категорий }\end{array}$ & $\begin{array}{l}\text { Личностно ориентированное обучение } \\
\text { на основе компетентного подхода } \\
\text { с использованием разных сред обучения } \\
\text { и «перевернутого класса» } \\
\text { Программы обеспечивают формирование } \\
\text { компетенций, востребованных на рынке труда, } \\
\text { а также легко адаптироваться в новых условиях } \\
\text { Студенты обучаются на основе партнерских } \\
\text { отношений с преподавателями, участвуя } \\
\text { в креативных проектах и др. видах работ, } \\
\text { стимулирующих самообразование; активно } \\
\text { сотрудничает со сверстниками; роль } \\
\text { преподавателя заключается в направлении } \\
\text { процесса обучения и контроле }\end{array}$ \\
\hline
\end{tabular}

и решения задач в рамках нормальной науки. Научное сообщество - это исследователи, принимающие парадигму. Нормальная наука - это развитие научного знания в рамках существующей парадигмы. В периоды нормальной науки члены научного сообщества не разрабатывают новые теории, а исследуют явления и расширяют теории, которые не противоречат схеме существующей парадигмы. Научная революция - это смена парадигмы, то есть переход от одной нормальной науки к другой [4-5]. Формирование парадигмы свидетельствует о зрелости научной дисциплины. Парадигма открывает перспективу решения ряда задач. Нормальная наука занимается реализацией этой перспективы.

Согласно Куну, новая парадигма (новый цикл) рождается из экспериментальной или теоретической аномалии, то есть явления, которое невозможно объяснить, опираясь на принятую парадигму. Это приводит к изменению категорий и процедур парадигмы, что нередко встречает сопротивление. Сопротивление отчасти связано с убежденностью, что, в конце концов, существующая парадигма позволит решить проблему. Но именно тщательный анализ выявленной аномалии и является импульсом для дальнейшего развития науки. Решение отказаться от парадигмы одновременно является решение принять новую парадигму. Значение кризисов заключается именно в том, что они сигнализируют о необходимости замены парадигмы и формировании новых компетенций оценки человеческого капитала [5]. Смена парадигмы (смена цикла) - это концепция, которая полностью меняет саму научную теорию развития всех областей знания и является сегодня классическим подходом к пониманию реальности.

Новая и современная парадигмы. Ключевым моментом в разрыве цепей старой парадигмы и принятии новой является образование. В сфере образования недостатки старого мышления в большинстве случаев вначале игнорируются, но со временем минусы старой системы становятся очевидными. Сегодня дискуссии о состоянии образования ведутся на всех уровнях правительственном, СМИ и в профессиональной среде; идет открытое и конструктивное обсуждение проблем высшей школы и среднего профессионального образования. Однако, если рассматривать сложившуюся ситуацию, связанную с процессом обучения и системой образования, в более широком контексте, то становится очевидным, что она сигнализирует о переходе к новой парадигме в образовании [4], которая совершенно по-другому оценивает человеческий капитал. Отказ от старой парадигмы, которая складывалась на протяжении многих веков, и формирование новой парадигмы, отвечающей вызовам новой сетевой эры, радикально изменит фундаментальные основы образования [5]: в таблице 1 показан ряд изменений, характеризующих новую парадигму в сравнении с парадигмой существующей.

Современная парадигма - это подход к образованию, которое является продуктом индустриальной эры 
и продолжает функционировать в эпоху сетевых технологий, когда доступ к информации обеспечивается практически повсеместно, благодаря цифровым технологиям. Переход от сегодняшней системы образования, созданной в эпоху промышленной революции, к системе, предназначенной для цифрового сетевого мира, является революционным [5].

Характеризуя переход к новой парадигме в развитых странах, необходимо отметить следующие изменения в системах образования:

- увеличивается негосударственное финансирования профессионального образования и широкое использование долговых, долевых и гибридных инструментов с участием государства в установлении норм и контролем их функционирования;

- высшее образование становится всеобщим и глобальным;

- количество учебных часов (периода обучения) не рассматривается как безусловный показатель качества образования;

- утверждается компетентностный подход к образованию, а ключевым моментом становится проектная деятельность;

- активизируется академическая мобильность и расширяется экспорт образовательных услуг;

- активно используются информационные технологии для создания новых форматов и типов обучения (ДПО, переподготовка, повышение квалификации), увеличивается доля корпоративного образования;

- расширяются внесистемные высоко диверсифицированные образовательные практики;

- система образования адаптируется к потребностям рынка труда;

- университеты становятся инновационными и предпринимательскими центрами;

- обеспечивается развитие человеческого капитала на всех этапах жизни: с раннего детства до старости [6-12].

Переход от одной парадигмы к другой - нелегкая задача. Сегодня наблюдается состояние неравновесия, когда существующая парадигма не позволяет решить назревшие проблемы, а новая еще не сформирована. Цикл исчезновения и создания парадигмы происходит на разных уровнях. Революция масштаба перехода от птолемеевского мира к коперниковскому происходит редко, в то время как более мелкие теории, которые впоследствии становятся частью более широкой парадигмы, рождаются достаточно часто.

Серьезные проблемы в образовании сегодня являются показателями того, что система находится в состоянии кризиса, что, в конечном итоге, приведет к смене парадигмы. Образование должно двигаться от модели, отвечающей требованиям индустриальной эпохи, к модели, способной ответить на вызовы эпохи сетевых технологий. Наблюдаемые сегодня педагогические, технологические и системные изменения в образовании, способствуют формированию новой парадигмы [13], которая базируется на следующих положениях:

- обучение на протяжении всей жизни признано правом каждого человека;

- глобальная демократизация знаний;

- становление общества глобальных знаний.

Эти изменения заставляют руководителей, преподавателей и исследователей сферы высшего образования фундаментально переосмыслить задачи и цели высшего образования, а также методологию. Кроме того, ряд деятелей на национальном и мировом уровне призывает пересмотреть высшее образование с точки зрения общечеловеческих ценностей и прав человека [14].

Барбара Давье, представитель по делам образования и культуры в ЮНЕСКО, использует следующую модель для иллюстрации концепции «равенство и справедливость как основа образования» [14]:

- демократические процессы принятия решений;

- разные поставщики образовательных услуг (при этом государство выступает в качестве гаранта равенства и справедливости).

Поскольку ни один институциональный тип не может удовлетворить образовательные потребности всех студентов и всех слоев общества, а также всех сегментов экономики, то очевидно, что разнообразный набор образовательных структур лучше справится с этой задачей. Таким образом, принципы равенства, справедливости и инклюзивности служат основой для создания диверсифицированной системы высшего образования, основополагающими целями которой являются:

- удовлетворение потребностей плюралистического демократического общества;

- соответствие требованиям постоянно меняющейся экономики;

- удовлетворение различных индивидуальных преференций.

С этой целью все большее число государственных и некоммерческих колледжей и университетов в Cоединенных Штатах пытаются сделать высшее образование более доступным для большего числа своих граждан. Например, штат Нью-Йорк предлагает бесплатное государственное высшее образование для способных студентов, а Народный университет предоставляет бесплатное высшее образование. Кроме того, этот университет являются одним из крупнейших поставщиков 
высшего образования для беженцев. Студенты, посещающие медицинский факультет Нью-Йоркского университета, больше не платят за обучение [14].

Доступность образования вдохновляет людей, которые теперь считают своим моральным долгом продолжать образование на протяжении всей жизни. Хотя бесплатное высшее образование не может устранить все расходы (например, расходы на проживание и альтернативные расходы), связанные с получением высшего образования, тем не менее, это еще на один шаг приближает студентов к реализации своих образовательных и жизненных планов.

Таким образом, четвертая промышленная революция, к которой подошла мировая экономика, означает грядущую автоматизацию практически всех процессов производства и создание единой национальной или наднациональной цифровой экосистемы.

Весь мир является свидетелем того, какими быстрыми темпами продолжается развитие каждого сектора экономики как на глобальном, так и на региональном уровне: разрабатываются новые технологии, создается принципиально новое оборудование, вводятся новые способы осуществления финансовых операций, появляются принципиально новые услуги, качество и уровень сложность которых постоянно растут,- все это становится возможным при возрастающем тренде ценности и эффективности человеческого капитала. Таким образом, «само развитие экономики создает онтологические предпосылки для формирования концепции человеческого капитала как составного элемента мировой цивилизации» [15].

Новые тенденции и новые знания, которые возникают, должны использоваться в области применения всех используемых производственных процессов и в области развития человеческого потенциала, а также в области содержания и уровня межличностных отношений. Точно так же, как технические инновации второй промышленной революции предъявили «новые требования к формам организации бизнеса, рациональному использованию всех ресурсов, развитию научной $\square$ организации труда, производства и управления» [15], а наука стала рассматриваться как производительная сила в ходе третьей промышленной революции, так и на пороге четвертой промышленной революции управление человеческим капиталом, который является активом любой организации, должно претерпеть философский сдвиг в своей практической реализации: от философии управления персоналом - к философии эффективного использования и развития человеческого потенциала. Такой философский подход предполагает изменение статуса сотрудника организации - он становится самым значимым ее ресурсом. Как следствие, вектор управление человеческим капиталом смещается в сторону создания мотивационных стимулов для эффективного участия сотрудников в производственных процессах организации. Развитие и управление людьми в соответствии с их ключевыми областями ответственности делают их не только незаменимым ресурсом в будущем, но и обеспечивают их стопроцентный вклад в работу организации. В то же время, нельзя не отметить, как указывает Р.М. Нуреев, что это «своеобразная форма капитала».

Таким образом, современная модель оценки компетенций человеческого капитала востребованных в высокотехнологичных и наукоемких отраслях экономик, должна отвечать следующим требованиям: обеспечивать оценку человеческого капитала на индивидуальном уровне, микроуровне (человеческий капитал организации) и макроуровне (региональном или национальном уровне); учитывать самооценку сотрудника в соответствии с существующими моделями компетентности; учитывать мотивационный аспект сотрудника; учитывать инвестиции работодателя в формирование, развитие и использование человеческого капитала; учитывать эффективность использование производственных затрат компании на развитие человеческого капитала.

\section{ЛИТЕРАТУРА}

1. Javier García Arenas Writing the future: the technological paradigm shift and the new economy [Электронный ресурс]. Режим доступа: https://www. caixabankresearch.com/en/writing-future-technological-paradigm-shift-and-new-economy

2. Satell, G. These 4 major paradigm shifts will transform the future of technology [Электронный ресурс]. Режим доступа: https://www.forbes.com/sites/ gregsatell/2016/05/15/these-4-major-paradigm-shifts-will-transform-the-future-of-technology/\#519ea0630b04

3. Кун, Т. (ред. Дмитриевой Н. В.). Структура научных революций: АСТ, 2014.-320 С.

4. Schieber, C. We are in the midst of a historic paradigm shift in education. [Электронный ресурс]. Режим доступа: https://www.competencyworks.org/highereducation-2/we-are-in-the-midst-of-a-historic-paradigm-shift-in-education/

5. Westacott, E. What is a paradigm shift? [Электронный ресурс]. Режим доступа: https://www.thoughtco.com/what-is-a-paradigm-shift-2670671

6. Диденко, Д. В. Зарубежный опыт применения финансовых инструментов для стимулирования системы образования /Д.В. Диденко // Деньги и кредит.2014.—№ 4.- - . 67-73. 
7. Измерение рейтингов университетов: международный и российский опыт / Под ред. Ф. Э. Шереги и А. Л. Арефьева. — М.: Центр социологических исследований, 2014.

8. Белогаш М.А., Мельничук М. В. Когнитивные аспекты развития информационно-образовательной среды в эпоху цифровизации // Российский гуманитарный журнал. 2020. Т. 9. № 2. С. 123-132.

9. Мельничук М.В., Грузина Ю. М., Фирсова И. А. Формирование научно-образовательных ценностей в системе мотивации молодежи // Экономические и социальные перемены: факты, тенденции, прогно3. 2019. Т. 12. № 6. С. 260-275.

10. Castelló-Climent, A. Human Capital Inequality, Life Expectancy and Economic Growth / A. Castelló-Climent, R. Doménech // The Economic Journal. — 2008. — No. 118 (528). - P. 653-677.

11. Docquier, F. Globalization, brain drain and development / F. Docquier, H. Rapoport // Journal of Economic Literature. — 2012. — No. 50 (3). — P. 681-730.

12. Ferreira, F.H.-G. The Measurement of Educational Inequality: Achievement and Opportunity / F.H.-G. Ferreira, J. Gignoux // The World Bank Economic Review.2013. - No. 28 (2). - P. 210-246.

13. Hanushek, E. A. Do better schools lead to more growth? Cognitive Skills, Economic Outcomes and Causation. / T. A. Hanushek, L. Woessmann // Journal of Economic Growth. 2012.- No. 17 (4). - P. 267-321.

14. Blessinger,P., Reshef,Sh., Sengupta, E.(2018)The shifting paradigm of higher education [Электронный ресурс]. Режим доступа:https://www.universityworldnews. com/post.php?story

15. Нуреев Р.М. Человеческий капитал и проблемы его развития в современной России // [Электронный ресурс]. Режим доступа: https://www.hse.ru/ data/357/727/BB.pdf

(c) Мельничук Марина Владимировна (MVMelnichuk@fa.ru).

Журнал «Современная наука: актуальные проблемы теории и практики»

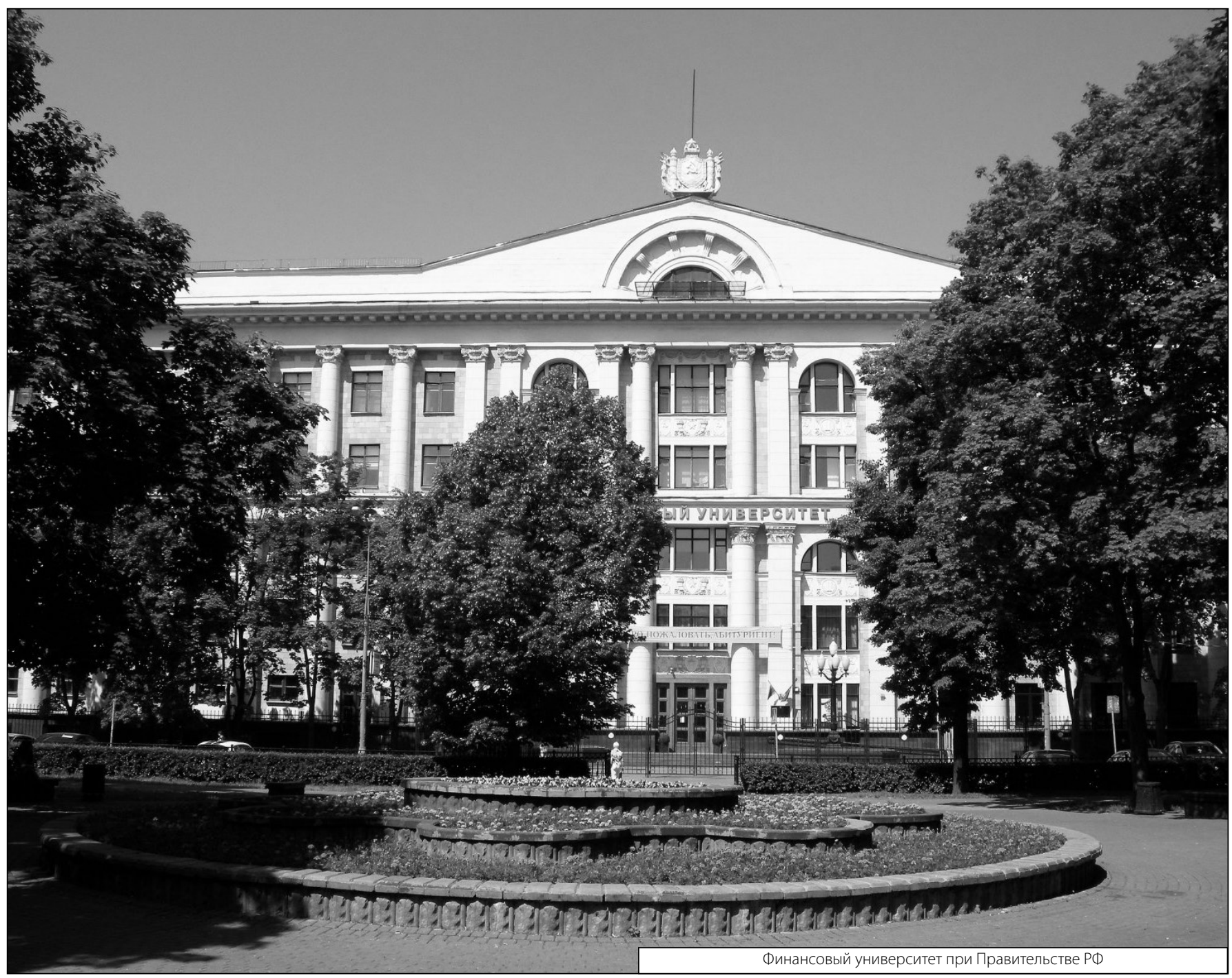

